\title{
Pengaruh Gaya Kepemimpinan, Komunikasi, dan Insentif terhadap Kinerja Karyawan pada PT. Romi Violeta Sidoarjo
}

\author{
*Kurnia Rahmadani, Mahmudah Enny Widyaningrum, Indah Noviandari \\ Prodi Manajemen Fakultas Ekonomi dan Bisnis Universitas Bhayangkara, Indonesia
}

\begin{abstract}
DOI: 10.46821/benchmark.v1i2.142
Abstrak

Tujuan penelitian ini adalah untuk mengetahui tentang pengaruh gaya kepemimpinan, komunikasi, dan insentif terhadap kinerja karyawan pada PT. Romi Violeta Sidoarjo. PT. Romi Violeta Sidoarjo merupakan salah satu perusahaan manufaktur dan pengekspor furniture terbesar di Indonesia, dengan spesialisasi produk di bidang rotan dan kayu. Dari beberapa faktor kinerja karyawan peneliti memilih gaya kepemimpinan, komunikasi, dan insentif karena dirasa ketiga variabel terdapat masalah pada PT. Romi Violeta Sidoarjo. Dalam penelitian ini yang menjadi responden adalah karyawan PT. Romi Violeta Sidoarjo dengan jumlah populasi 120 orang dan 92 responden dari jumlah populasi peneliti menggunakannya sebagai sampel penelitian diambil dengan metode proportionate stratified random sampling. Data yang digunakan dalam penelitian ini adalah data primer yang diperoleh dengan menyebarkan kuisioner kepada seluruh karyawan. Teknik analisis data yang digunakan adalah analisis regresi linier berganda dengan menggunakan uji $\mathrm{F}$, uji $\mathrm{T}$, serta melihat pengaruh dominan dengan taraf signifikan 5\%. Hasil pengujian terbukti bahwa variabel Gaya Kepemimpinan, Komunikasi, dan Insentif berpengaruh secara simultan dan signifikan terhadap Kinerja Karyawan dengan hasil regresi linier berganda dalam uji $F$ diperleh nilai $F_{\text {hitung }} 73,277$ lebih besar dari $F_{\text {tabel }} 2,71$ dan nilai signifikan yang dihasilkan sebesar 0,000 lebih kecil dari $\alpha$ sebesar 0.05 . Sedangkan pengaruh secara parsial dan signifikan melalui uji $\mathrm{T}$ diperoleh $\mathrm{T}_{\text {hitung }}$ untuk masing-masing variabel bebas yaitu variabel Gaya Kepemimpinan $\left(\mathrm{X}_{1}\right)$ sebesar 3,887, Komunikasi $\left(\mathrm{X}_{2}\right)$ sebesar 2,963, dan Insentif $\left(\mathrm{X}_{3}\right)$ sebesar 4,253 lebih besar dari $T_{\text {tabel }}$ sebesar 1,991, maka variabel Gaya Kepemimpinan, Komunikasi, dan Insentif berpengaruh secara parsial dan signifikan terhadap variabel Kinerja Karyawan. Sedangkan variabel Insentif berpengaruh dominan terhadap Kinerja Karyawan pada PT. Romi Violeta Sidoarjo dengan dengan koefisien $\beta$ (beta) terbesar yaitu 0,378 .
\end{abstract}

Kata kunci : Gaya Kepemimpinan, Komunikasi, Insentif, Kinerja Karyawan

\begin{abstract}
The purpose of this study was to find out about the influence of leadership style, communication, and incentives on employee performance at PT. Romi Violeta Sidoarjo. PT. Romi Violeta Sidoarjo is one of the largest furniture manufacturing and exporting companies in Indonesia, specializing in rattan and wood products. Of the several employee performance factors the researchers chose leadership, communication, and incentive styles because they felt that there were three problems with PT. Romi Violeta Sidoarjo. In this study the respondents were employees of PT. Romi Violeta Sidoarjo with a population of 120 people and 92 respondents from the total population of researchers using it as a study sample taken with proportionate stratified random sampling method. The data used in this study are primary data obtained by distributing questionnaires to all employees. Data analysis technique used is multiple linear regression analysis using the $\mathrm{F}$ test, $\mathrm{T}$ test, and see the dominant influence with a significant level of $5 \%$. The test results proved that the variables of Leadership Style, Communication, and Incentives simultaneously and significantly influence Employee Performance with the results of multiple linear regression in the F test obtained by Fcount value of 73.277 is greater than Ftable 2.71 and the resulting significant value of 0,000 is smaller than $\alpha$ of 0.05 . While the partial and significant influence through the $\mathrm{T}$ test was obtained by Thitung for each independent variable, namely the Leadership Style variable (X1) of 3.887, Communication (X2) of 2.963, and Incentives (X3) of 4.253 greater than the table of 1.991, then the variable Leadership Style, Communication, and Incentives partially and significantly influence Employee Performance variables. While the Incentive variable has a dominant effect on Employee Performance at PT. Romi Violeta Sidoarjo with the biggest coefficient $\beta$ (beta) is 0.378 .
\end{abstract}

Keywords: Leadership Style, Communication, Incentives, Employee Performance

*Corresponding Author:

Hal: 49-57

Email: kurniarahmadhani06@gmail.com 
Pada era globalisasi di dunia, setiap negara harus ikut atau dipaksa ikut dalam percaturan globalisasi dunia.Perekonomian dari berbagai belahan dunia menunjukan perkembangannya dalam era globalisasi seperti saat ini, tujuannya yaitu untuk menyejahterakan masyarakat negara itu sendiri.

Menurut Prasetyo (2018:1), Sumber daya manusia merupakan salah satu faktor kunci utama dalam persaingan global yang menunjukkan bahwa sumber daya manusia harus diperhatikan dalam segala kebutuhannya bagaimana menciptakan dan mengelola sumber daya manusia menjadi berkualitas, memiliki ketrampilan serta berdaya saing tinggi dalam persaingan global untuk mencapai tujuan perusahaan.

PT. Romi Violeta Sidoarjo adalah salah satu perusahaan manufaktur dan pengekspor furniture terbesar di Indonesia, dengan spesialisasi produk di bidang rotan dan kayu.PT. Romi Violeta selain menjual produk pada pasar dalam negeri, mereka juga menjual pada pasar luar negeri seperti di negara-negara yang ada di Benua Eropa, Benua Amerika, Benua Afrika, Benua Asia.

Kinerja karyawan merupakan faktor penting bagi setiap perusahaan untuk dapat meningkatkan produktivitas dan profit.Hal inilah yang dapat menentukan perusahaan dapat tumbuh dan berkembang.Dengan mengetahui kinerja, perusahaan akan lebih mengetahui seberapa jauh pengembangan mutu sumber daya manusia yang telah berhasil dengan efektif.

Riinawati (2019:153) Gaya kepemimpinan adalah suatu ciri yang digunakan pimpinan untuk memengaruhi bawahan agar sasaran organisasi tercapai atau dapat pula dikatakan bahwa gaya kepemimpinan adalah pola perilaku dan strategi yang disukai dan sering diterapkan oleh seorang pemimpin. Seorang pemimpin yang baik adalah ketika mampu untuk memanfaatkan seluruh sumber daya manusia yang dimilikinya, sehingga kepemimpinan menjadi bagian penting dalam meningkatkan kinerja pegawai.

Komunikasi adalah pertukaran informasi atau pesan secara dua arah antara komunikator dan komunikan, baik langsung maupun tidak langsung, baik menggunakan maupun tidak menggunakan media (Busro, 2018:207). Komunikasi diperlukan untuk menjalin hubungan saling menghargai, hormat-menghormati sesamanya, toleransi dari hati ke hati, dalam rangka satu tujuan untuk menyukseskan pekerjaan dengan baik sebagaimana yang diharapkan oleh perusahaan. Dengan adanya hubungan komunikasi dalam suatu organisasi akan dapat meningkatkan kinerja karyawan.

Menurut Heidjrachman dalam Gaol (2019:334), Insentif adalah pengupahan dimaksudkan untuk memberikan upah/gaji yang berbeda karena prestasi kerja yang berbeda. Pemberian insentif dimaksudkan agar dapat memenuhi kebutuhan para karyawan dan keluarga mereka. Insentif diberikan untuk mendorong karyawan agar lebih giat dan semangat bekerja lebih produktif lagi, dan mencapai tingkat kinerja yang lebih tinggi prestasinya dalam mencapai tujuan perusahaan.

\section{TINJAUAN PUSTAKA}

\section{Pengertian Organisasi}

Menurut Oliver Shelsom, John M. Phiffner, S.Owen Lane dalam Riinawati (2019:200), organisasi adalah penggabungan kerja orang-orang atau sekelompok orang yang memiliki kemampuan untuk melaksanakan tugas-tugas. 
Pengertian Perilaku Organisasi

Menurut Stephen P. Robbins dan Timothy A. Judge dalam Nuryadin (2019:1) Perilaku organisasi adalah bidang studi yang menyelidiki pengaruh antar individu, kelompok dan struktur terhadap perilaku dalam organisasi, untuk menciptakan organisasi yang lebih efektif.

\section{Pengertian Manajemen Sumber Daya Manusia}

Menurut Stoner dalam Suhardi (2018:217), manajemen sumber daya manusia adalah suatu prosedur yang berkelanjutan yang bertujuan untuk memasok suatu organisasi atau perusahaan dengan orang-orang yang tepat untuk ditempatkan pada posisi jabatan yang tepat pada saat organisasi memerlukannya.

\section{Pengertian Gaya Kepemimpinan}

Gaya kepemimpinan adalah perilaku atau cara yang dipilih dan dipergunakan pemimpin dalam mempengaruhi pikiran, perasaan, sikap, dan perilaku para anggota organisasi atau bawahannya menurut Sudaryono dalam (Tohirin, 2019:106).

\section{Indikator Gaya Kepemimpinan}

Menurut Mujiati (2016:7968), indikator dalam mengukur variabel gaya kepemimpinan meliputi:

1. Sikap pimpinan

2. Keberanian menerima risiko

3. Ketepatan pendelegasian wewenang

4. Kemampuan memimpin

5. Visioner

\section{Pengertian Komunikasi}

Menurut Sinambela (2016:455), komunikasi berarti adanya kesamaan makna antara komunikator dan komunikan dengan tujuan mengubah sikap, opini, atau pandangan/perilaku orang lain tentang pesan yang disampaikan.

\section{Indikator Komunikasi}

Menurut Rizky (2017:48), indikator-indikator dalam komunikasi antara lain:

a. Kemudahan dalam memperoleh informasi

b. Intensitas komunikasi

c. Efektivitas komunikasi

d. Tingkat pemahaman pesan

e. Perubahan sikap

\section{Pengertian Insentif}

Insentif menurut Mulyadi (2016:81), adalah salah satu kompensasi atau imbalan yang diberikan kepada karyawan dan tidak ada kaitannya dari upah atau gaji, atas dasar menghasilkan produk yang melebihi target yang ditentukan.

\section{Indikator Insentif}

Menurut Robert dalam Sari (2017:24), indikator-indikator untuk menilai pemberian 
insentif yaitu:
a. Kinerja
b. Lama kerja
c. Senioritas
d. Kebutuhan
e. Keadilan dan kelayakan
f. Evaluasi Jabatan

\section{Pengertian Kinerja Karyawan}

Tohirin (2019:35), mengemukakan kinerja merupakan pencapaian kerja karyawan, baik secara individu ataupun kelompok, yang dilaksanakan sesuai dengan tugas dan tanggung jawab yang diberikan, berdasarkan kualitas ataupun kuantitas kerja yang dihasilkan.

\section{Indikator Kinerja Karyawan}

Menurut Crimson dalam Usadi (2018:58), ada enam indikator untukmengukur sejauh mana pegawai mencapai suatu kinerja secara individual sebagai berikut:
a. Kualitas
b. Kuantitas
c. Ketepatan waktu
d. Efektifitas
e. Kemandirian
f. Komitmen organisasi

\section{Hipotesis}

a. Bahwa variabel gaya kepemimpinan, komunikasi, dan insentif berpengaruh secara simultan dan signifikan terhadap variabel kinerja karyawan pada PT. Romi Violeta Sidoarjo

b. Bahwa variabel gaya kepemimpinan, komunikasi, dan insentif berpengaruh secara parsial dan signifikan terhadap variabel kinerja karyawan pada PT. Romi Violeta Sidoarjo.

c. Bahwa variabel gaya kepemimpinan berpengaruh dominan terhadap variabel kinerja karyawan pada PT. Romi Violeta Sidoarjo.

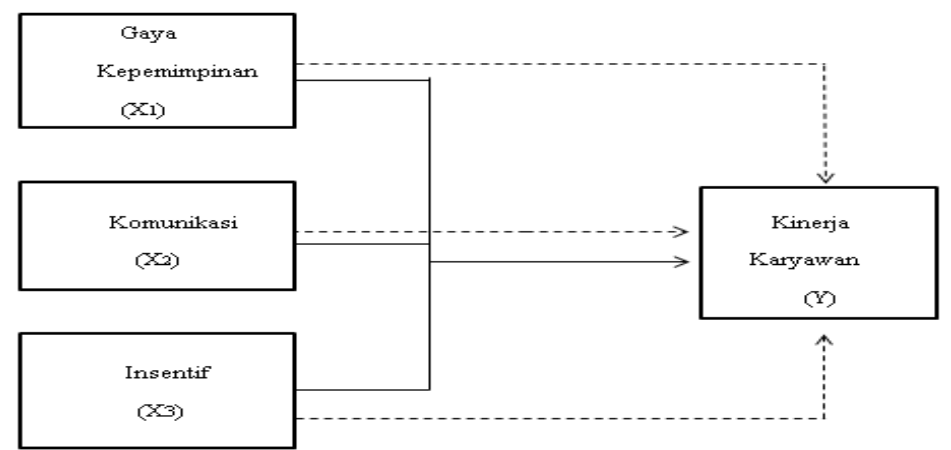

Sumber: Peneliti (2020)

Gambar 1

Kerangka Konseptual 


\section{METODE PENELITIAN}

\section{Populasi}

Dalam penelitian ini yang menjadi populasi adalah karyawan PT. Romi Violeta Sidoarjo sebanyak 120 karyawan.

\section{Sampel}

Berdasarkan hasil perhitungan menggunakan rumus slovin dengan tingkat kesalahan 5\% didapatkan hasil 92 responden karyawan PT. Romi Violeta Sidoarjo.

\section{HASIL ANALISIS DAN PEMBAHASAN}

\section{Uji Validitas}

Dari tabel 1 menunjukkan bahwa dari indikator-indikator variabel yang digunakan dalam penelitian ini semuanya memiliki nilai korelasi(rhitung) $>0,1726$. Hal ini berarti bahwa semua indikator yang digunakan untuk mengukur semua variabel dalam penelitian ini dinyatakan valid.

\section{Uji Reliabilitas}

Berdasarkan tabel 2 terlihat bahwa variabel bebas yang terdiri dari Gaya Kepemimpinan (X1), Komunikasi (X2), dan Insentif (X3), serta variabel terikat Kinerja Karyawan (Y) masing-masing memiliki nilai AlphaCronbach $>0,70$. Kondisi ini memberikan arti bahwa seluruh variabel tersebut adalah reliabel dan dapat digunakan pada analisis selanjutnya.

\section{Analisis Regresi Linear Berganda}

Berdasarkan tabel di atas, maka persamaan regresi yang terbentuk pada uji regresi ini adalah:

$\mathrm{Y}=\mathrm{a}+\mathrm{b} 1 \mathrm{X} 1+\mathrm{b} 2 \mathrm{X} 2+\mathrm{b} 3 \mathrm{X} 3$

$\mathrm{Y}=0,461+0,313 \mathrm{X}_{1}+0,242 \mathrm{X}_{2}+0,326 \mathrm{X}_{3}$

Model tersebut dapat diinterpretasikan sebagai berikut:

a. Konstanta(a) sebesar 0,461memberi arti apabila variabel Gaya Kepemimpinan, Komunikasi, dan Insentif adalah bernilai konstan, maka besarnya variabel terikat Kinerja Karyawan adalah bernilai sebesar 0,461 satuan.

b. Gaya Kepemimpinan (X1) memiliki nilai koefisien sebesar 0,313. Hal ini menandakan bahwa koefisien variabel gaya kepemimpinan (X1) memiliki pengaruh positif (searah) terhadap kinerja karyawan (Y). Apabila gaya kepemimpinan bertambah satu satuan, maka kinerja karyawan akan bertambah sebesar 0,313 satuan. Artinya semakin tinggi nilai gaya kepemimpinan maka semakin tinggi kinerja karyawan.

c. Komunikasi (X2) memiliki nilai koefisien sebesar 0,242. Hal ini menandakan bahwa koefisien variabel Komunikasi (X2) memiliki pengaruh positif (searah) terhadap Kinerja Karyawan (Y). Apabila komunikasi bertambah satu satuan, maka kinerja karyawan akan bertambah sebesar 0,242 satuan.Artinya semakin tinggi nilai komunikasi, maka semakin tinggi kinerja karyawan.

d. Insentif(X3) memiliki nilai koefisien 0,326. Hal ini menandakan bahwa koefisien variabel Insentif (X3)memiliki pengaruh positif (searah) terhadap kinerja karyawan (Y). Apabila Insentif bertambah satu satuan, maka kinerja karyawan akan bertambah 0,326 satuan. Artinya semakin baik insentif yang ada di perusahaan maka semakin tingi pula kinerja karyawan. 
Hasil Perhitungan Uji Validitas

\begin{tabular}{lccc}
\hline Variabel/Indikator & $\mathrm{r}_{\text {hitung }}$ & $\mathrm{r}_{\text {tabel }}$ & Keterangan \\
Gaya Kepemimpinan (X1) & & & \\
\hline X1.1 & 0.715 & 0,1726 & Valid \\
X1.2 & 0.814 & 0,1726 & Valid \\
X1.3 & 0.820 & 0,1726 & Valid \\
X1.4 & 0.828 & 0,1726 & Valid \\
X1.5 & 0.785 & 0,1726 & Vaid \\
Komunikasi (X2) & & & \\
X2.1 & 0.637 & 0,1726 & Valid \\
X2.2 & 0.666 & 0,1726 & Valid \\
X3.3 & 0.695 & 0,1726 & Valid \\
X2.4 & 0.780 & 0,1726 & Valid \\
X2.5 & 0.722 & 0,1726 & Valid \\
Insentif (X3) & & & \\
X3.1 & 0.706 & 0,1726 & Valid \\
X3.2 & 0.808 & 0,1726 & Valid \\
X3.3 & 0.682 & 0,1726 & Valid \\
X3.4 & 0.727 & 0,1726 & Valid \\
X3.5 & 0.758 & 0,1726 & Vaid \\
Kinerja Karyawan (Y) & & & \\
Y1 & 0.568 & 0,1726 & Valid \\
Y2 & 0.745 & 0,1726 & Valid \\
Y3 & 0.809 & 0,1726 & Valid \\
Y4 & 0.621 & 0,1726 & Valid \\
Y5 & 0.703 & 0,1726 & Valid \\
\hline S
\end{tabular}

Sumber: Data diolah peneliti (2020)

Tabel 2

Hasil Perhitungan Uji Reliabilitas

\begin{tabular}{lcc}
\hline Variabel & Nilai Alpha & Keterangan \\
\hline Gaya Kepemimpinan (X1) & 0.852 & Reliabel \\
Komunikasi (X2) & 0.733 & Reliabel \\
Insentif (X3) & 0.787 & Reliabel \\
Kinerja Karyawan (Y) & 0.722 & Reliabel \\
\hline
\end{tabular}

Sumber: Data diolah peneliti (2020)

Berdasarkan tabel 3 dapat diketahui bahwa nilai Fhitung sebesar 73,277 sedangkan Ftabel (dengan tingkat kepercayaan $\alpha$ sebesar 0,05) adalah 2,71, karena Fhitung lebih besar dari Ftabel maka H0 ditolak H1 diterima, sehingga dapat disimpulkan bahwa variabel bebas gaya kepemimpinan (X1), komunikasi (X2), dan insentif (X3), secara simultan berpengaruh signifikan terhadap variabel kinerja karyawan $(\mathrm{Y})$.

Dari tabel 3 variabel gaya kepemimpinan didapatkan hasil uji Thitung $(3,887)>$ Ttabel (1,98729). Dapat disimpulkan bahwa variabel gaya kepemimpinan secara parsial berpengaruh positif signifikan terhadap variabel kinerja karyawan. 
Tabel 3

Model Persamaan Regresi

\begin{tabular}{|c|c|c|c|c|c|c|}
\hline \multicolumn{7}{|c|}{ Coefficients $^{\mathrm{a}}$} \\
\hline & & \multicolumn{2}{|c|}{$\begin{array}{c}\text { Unstandardized } \\
\text { Coefficients }\end{array}$} & $\begin{array}{l}\text { Standardized } \\
\text { Coefficients }\end{array}$ & & \\
\hline \multicolumn{2}{|c|}{ Model } & B & Std. Error & Beta & $\mathrm{t}$ & Sig. \\
\hline \multirow[t]{5}{*}{1} & (Constant) & .461 & .248 & & 1.858 & .067 \\
\hline & Gaya & .313 & .081 & .359 & 3.887 & .000 \\
\hline & Kepemimpinan & & & & & \\
\hline & Komunikasi & .242 & .082 & .218 & 2.963 & .004 \\
\hline & Insentif & .326 & .077 & .378 & 4.253 & .000 \\
\hline
\end{tabular}

a. Dependent Variable: Kinerja Karyawan

Fhitung $=73,277$

Fsig $=0,000$

$\mathrm{R} 2=0,714$

$\mathrm{N}=92$

Sumber: Data diolah peneliti (2020)

Dari tabel 3 variabel komunikasi didapatkan hasil uji Thitung (2,963) > Ttabel(1,98729). Dapat disimpulkan bahwa variabel komunikasi secara parsial berpengaruhpositif signifikan terhadap variabel kinerja karyawan.

Dari tabel 3 variabel insentif didapatkan hasil uji Thitung (4,253) > Ttabel (1,98729). Dapat disimpulkan bahwa variabel insentif secara parsial berpengaruh positif signifikan terhadap variabel kinerja karyawan.

Dari tabel 3 Adapun nilai koefisien determinasi (R2) didapatkan sebesar 0,714 atau sebesar $71 \%$ artinya bahwa variabel bebas mempunyai pengaruh terhadap variabel terikat sebesar $71 \%$, sedangkan sisanya sebesar $29 \%$ dipengaruhi oleh faktor lain diluar variabel penelitian ini.

Dari tabel 3 menunjukkan bahwa variabel insentif memiliki koefisien $\beta$ (beta) terbesar yaitu 0,378, sehingga dapat disimpulkan bahwa variabel bebas yang mempunyai pengaruh dominan terhadap variabel terikat kinerja karyawan adalah variabel insentif.

\section{SIMPULAN DAN SARAN}

Berdasarkan hasil penelitian dan pembahasan tentang pengaruh gaya kepemimpinan, komunikasi, dan insentif terhadap kinerja karyawan yang digunakan sesuai dengan hipotesis yang dilakukan dengan menggunakan analisis regresi linier berganda, maka dapat ditarik kesimpulan sebagai berikut: Variabel gaya kepemimpinan (X1), komunikasi (X2), dan insentif (X3) secara simultan berpengaruh signifikan terhadap Kinerja Karyawan (Y). Dengan hasil analisis uji F diperoleh nilah Fhitung $(73,277)>$ Ftabel $(2,71)$ dengan tingkat signifikansi sebesar $0,000<0,05$. Sehingga dapat disimpulkan bahwa H0 ditolak dan H1 diterima, bahwa Gaya Kepemimpinan, Komunikasi, dan Insentif jika ditingkatkan bersama-sama maka akan meningkatkan kinerja karyawan pada PT. Romi Violeta Sidoarjo. Gaya Kepemimpinan (X1) secara parsial berpengaruh positif dan signifikan terhadap Kinerja Karyawan (Y) pada PT. Romi Violeta Sidoarjo. Dengan hasil uji T untuk variabel Gaya Kepemimpinan diperoleh nilai Thitung $(3,887)>$ Ttabel $(1,98729)$ dengan tingkat signifikansi sebesar $0,000<0,05$. Sehingga dapat disimpulkan 
bahwa H0 ditolak dan H1 diterima, bahwa Gaya Kepemimpinan yang diterapkan pimpinan berjalan dengan baik dan tepat maka akan meningkatkan kinerja karyawan pada PT. Romi Violeta Sidoarjo. Komunikasi (X2) secara parsial berpengaruh positif dan signifikan terhadap Kinerja Karyawan (Y) pada PT. Romi Violeta Sidoarjo. Dengan hasil uji T untuk variabel Komunikasi diperoleh nilai Thitung $(2,963)>$ Ttabel $(1,98729)$ dengan tingkat signifikansi sebesar 0,004 < 0,05. Sehingga dapat disimpulkan bahwa H0 ditolak dan H1 diterima, bahwa Komunikasi karyawan terjalin dengan baik, maka akan diikuti dengan meningkatnya kinerja karyawan pada PT. Romi Violeta Sidoarjo. Insentif (X3) secara parsial berpengaruh positif dan signifikan terhadap Kinerja Karyawan (Y) pada PT. Romi Violeta Sidoarjo. Dengan hasil uji T untuk variabel Insentif diperoleh nilai Thitung $(4,253)>$ Ttabel $(1,98729)$ dengan tingkat signifikansi sebesar 0,000 $<0,05$. Sehingga dapat disimpulkan bahwa H0 ditolak dan H1 diterima, bahwa Insentif yang diberikan oleh PT. Romi Violeta Sidoarjo sesuai dengan kualitas dan kuantitas pekerjaan maka secara otomatis akan meningkatkan kinerja karyawan pada PT. Romi Violeta Sidoarjo. Variabel Insentif (X3) berpengaruh dominan terhadap Kinerja Karyawan (Y) dengan nilai koefisien $\beta$ (beta) terbesar yaitu 0,378, yang diartikan bahwa semakin tinggi kinerja karyawan maka, semakin besar pula pemberian insentif oleh perusahaan untuk meningkatkan kinerja karyawan terhadap output yang dihasilkan, namun sistem insentif di PT. Romi Violeta Sidoarjo ini tidak normatif.

\section{DAFTAR PUSTAKA}

Busro, M. 2018. Teori-teori Manajemen Sumber Daya Manusia. Jakarta: Prenadamedia group.

Gaol, C. J. 2019. Human Capital Manajemen Sumber Daya Manusia. Jakarta: PT. Grasindo Anggota Ikapi.

Mujiati, K. a. 2016. Pengaruh Gaya Kepemimpinan Dan Kompensasi Terhadap Kinerja Karyawan PT. Astra Honda Nusa Dua Kabupaten Badung. E-jurnal manajemen unud, 7968.

Mulyadi. 2016. Manajemen Sumber daya Manusia (MSDM). Bogor: In media.

Nuryadin, D. 2019. Perilaku Organisasi Modern Dilengkapi Perspektif Islam. Jakarta: Mitra Wacana Media.

Prasetyo, R. 2018. Pengarub Gaya Kepemimpinan, Motivasi Dan Disiplin Kerja Terbadap Kinerja Karyawan PT. Adira Multi Finance Di Surabaya. Ekonomi manajemen, 1.

Riinawati. 2019. Pengantar Teori Manajemen Komunikasi dan Organisasi. Yogyakarta: PT. Pustaka Baru.

Rizky, R. c. 2017. Pengaruh Komunikasi, Sikap Pimpinan Dan Lingkungan Kerja Terbadap Kinerja Karyawan Pada PT. Golden Tanggub Pratama Sidoarjo. manajemen, 16.

Sari, D. n. 2017. Pengarub Insentif, Disiplin Kerja, Dan Pengembangan Karir Terbadap Semangat Kerja Karyawan PT. Matahari Departmen Store Cito Surabaya . manajemen, 21.

Sinambela, L. P. 2016. Manajemen Sumber Daya Manusia. Jakarta: PT. Bumi Aksara. 
Suhardi. 2018. Pengantar Manajemen Dan Aplikasinya. Yogyakarta: Gava media.

Tohirin. 2019. Perilaku Organisasi Modern Dilengkapi Dengan Perspektif Islam. Jakarta: Mitra Wacana Media.

Usadi, R. p. 2018. Pengaruh Gaya Kepemimpinan, Motivasi Dan Disiplin Kerja Terbadap Kinerja Karyawan PT. Adira Multi Finance Di Surabaya. manajemen. 